\title{
Influence of Grouting-material Compressive-strength on the Mechanical Properties of Grouting-sleeve Reinforcement-connection Component
}

\author{
Fan $\mathrm{Gu}^{1}$, a , Aike Xian ${ }^{1}$, Weijian Zhao ${ }^{1}$, Wei Wei $^{1}$ \\ ${ }^{1}$ Civil Engineering College, Shenyang Jianzhu University, China \\ aguzhaozheng@yeah.net
}

\begin{abstract}
Keywords: Grouting-sleeve Reinforcement-connection Component; Axial Tension Load; Stress Distribution; Grouting-material Compressive-strength; ABAQUS

Abstract. By means of ABAQUS, the numerical model of grouting-sleeve reinforcement-connection component under the action of axial tension load was established, and the influence of groutingmaterial compressive-strength on the stress distribution, the displacement distribution at groutingmaterial, reinforcement and sleeve were gotten. Numerical simulation shows that with the change of grouting-material compressive-strength, the stress distribution and the displacement distribution at reinforcement and sleeve are almost invariable. Meanwhile, with the increase of grouting-material compressive-strength from $60 \mathrm{MPa}$ to $140 \mathrm{MPa}$, the minimum principal stress at grouting-material trends to decrease slightly, as well as the maximum displacement value at grouting-material trends to decrease simultaneously, which implies component be in a more stable work condition.
\end{abstract}

\section{Introduction}

Nowadays, reinforcement-connection technology by means of grouting-sleeve is widely adopted in prefabricated housing, with its advantages of high strength, reliable performance, energy saving, convenient and fast construction, etc. Reinforcement-connection technology by grouting-sleeve is that two steel reinforcement bars are inserted into the ductile iron sleeve with internal annular ribs firstly, and then grouting-material with characteristics of high strength, earlier strength, slight expansion and great fluidness is injected into sleeve by filling equipment [1][2]. When grouting- material hardening, two steel reinforcement bars are connected together firmly. As is well known, the grouting-material compressive-strength can severely impact the connecting reliability of grouting- sleeve reinforcement-connection component. In this paper, the numerical models of grouting-sleeve reinforcement-connection component with different grouting-material compressive-strength were established, and the stress distribution, displacement distribution at grouting-material, reinforcement and sleeve under the action of axial tension load were gotten. Furthermore, according to numerical calculation data, the influence of grouting-material compressive-strength on connecting performance of component were analyzed, which provides reference to the optimal design of component.

\section{Numerical Simulation of Grouting-sleeve Reinforcement-connection Component}

On the basis of the actual structure of grouting-sleeve for connecting $\Phi 25 \mathrm{~mm}$ reinforcements, five finite element numerical models of grouting-sleeve reinforcement-connection component with different grouting-material compressive-strength from $60 \mathrm{MPa}$ to $140 \mathrm{MPa}$ were built. For reducing the number of elements, 1/2 model in axial direction was selected, and the solid numerical models of reinforcement, grouting-material and sleeve are as shown in Figure1 (a) - (c) respectively. The overall numerical model of component is as shown in Figure1 (d), with $x y$ plane-symmetry displacement boundary conditions on the bottom surface of numerical model, which is the middle cross section in axial direction of component. Meanwhile, by stress control mode, the axial tension load was exerted on the top end of the solid numerical model of reinforcement, with the amplitude of $570 \mathrm{MPa}$, which is the tensile strength of HRB400 reinforcement. The mesh generation of component model is as shown in Figure1 (e). In the process of building numerical model, the concrete damaged plasticity model [3] was adopted for representing grouting-material constitutive relation, which means that tension crack and 
crushed destruction are the failure mechanism of grouting-material. Meanwhile, the constitutive data of grouting-material [4][5], the constitutive data of HRB400 reinforcement and ductile iron with reference to literature [6][7] were adopted as their stress-strain relation respectively.

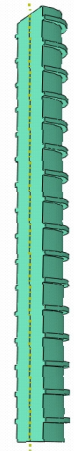

(a)

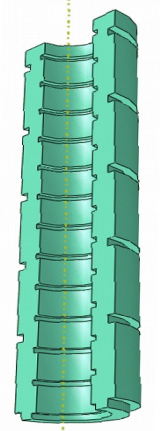

(b)

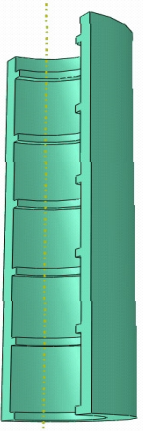

(c)

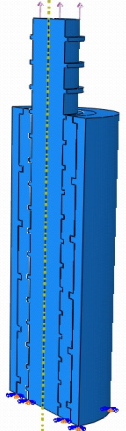

(d)

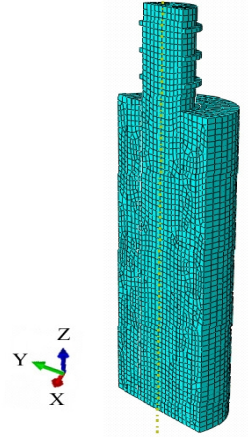

(e)

Fig.1. Numerical model of grouting-sleeve reinforcement-connection component

\section{Results and Discussion}

When the value of grouting-material compressive-strength assigned $60 \mathrm{MPa}, 80 \mathrm{MPa}, 100 \mathrm{MPa}$, $120 \mathrm{MPa}$ and $140 \mathrm{MPa}$, the Mises stress nephograms of grouting-sleeve reinforcement-connection component were gotten, as shown in Figure2 (a) - (e) respectively. In each figure, the top end represents the end of real sleeve, as well as the bottom end represents the middle cross section of real componet due to the half model in axial direction selected as mentioned above.

From Figure2, it is obvious that the value of the Mises stress at reinforcement bars increases form the free end within sleeve to the loaded end in axial direction, and the Mises stress distributions upon sleeve-wall and sleeve-rib represent contrary variational trend. From the mid-span section to the free end section in axial direction, the value of Mises stress at sleeve-wall decreases, whereas that at sleeve-rib increases, which implies that the mid-span cross section of sleeve-wall and the first rib at the free end of sleeve are the most dangerous portion. Meanwhile, Figure 2 also shows that whatever the change of grouting-material compressive-strength, the distribution trends and the values of the Mises stress at reinforcement bars and sleeve are almost invariable.

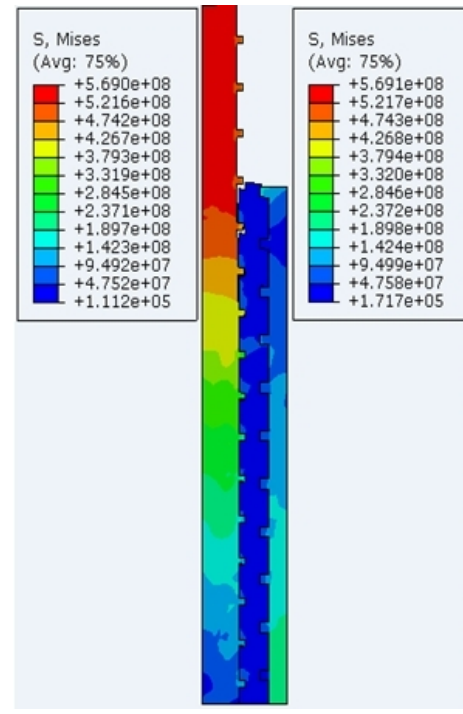

(a)

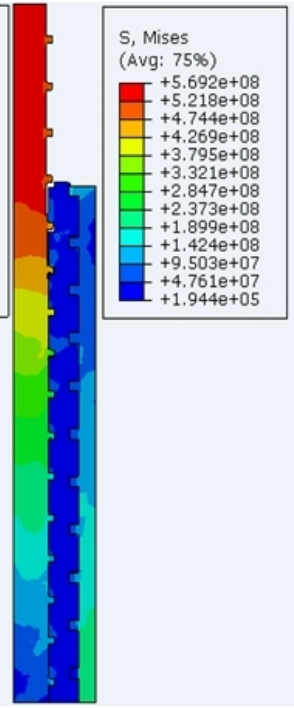

(b)

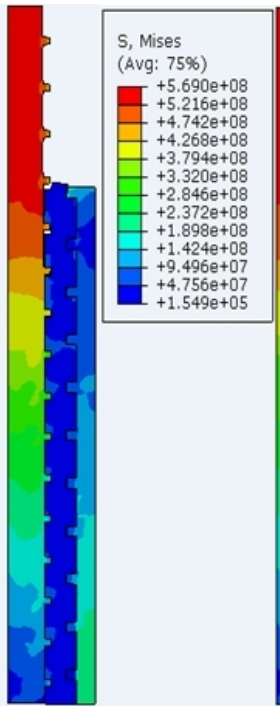

(c)

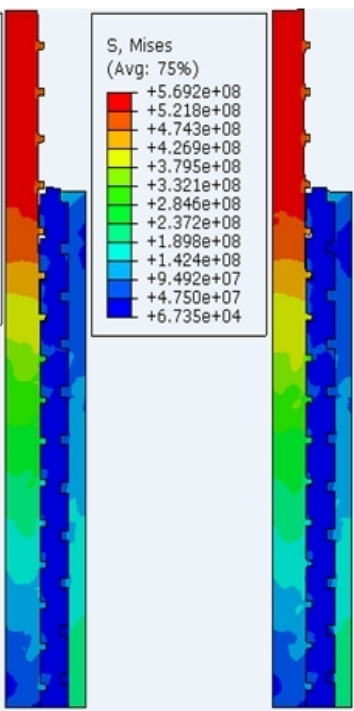

(d) (e)

Fig.2. The Mises stress nephograms of grouting-sleeve reinforcement-connection component 
It is well known that grouting-material mainly bears compressive load due to its characteristic, thus the minimum principal stress nephograms of grouting-material were gotten as shown in Figure3 (a) (e), corresponding to the values of grouting-material compressive-strength of $60 \mathrm{MPa}, 80 \mathrm{MPa}$, $100 \mathrm{MPa}, 120 \mathrm{MPa}$ and $140 \mathrm{MPa}$ respectively.

Figure 3 shows that the minimum principal stress at grouting-material is almost compressive, and from loaded end to non-loaded end along axial direction, the absolute value of the minimum principal stress at grouting-material trends to be decreased. In addition, between reinforcement rib and sleeve rib, sloping compression zone in grouting-material is formed to transfer load between reinforcement and sleeve. Furthermore, on the interface of reinforcement rib and sleeve rib, the absolute value of the minimum principal stress at grouting-material is obviously bigger, particularly in the region contacting with the first reinforcement rib form loaded end, being close to the axial compressive strength of grouting-material. When the value of grouting-material compressive-strength being assigned $60 \mathrm{MPa}$, $80 \mathrm{MPa}, 100 \mathrm{MPa}, 120 \mathrm{MPa}$ and $140 \mathrm{MPa}$, the values of the minimum principal stress at grouting-material on the most dangerous point as mentioned above are $-128 \mathrm{MPa},-126 \mathrm{MPa},-128 \mathrm{MPa}$, $-118 \mathrm{MPa}$ and $-113 \mathrm{MPa}$ respectively. It is obvious that adopting the grouting-material with higher compressive-strength, the largest absolute value of the minimum principal stress at grouting- material could be decrease due to stress redistribution. Considering the compressive-strength of grouting-material, it can be seen that the compressive-strength of grouting-material should be in the range of $100 \mathrm{MPa}-120 \mathrm{MPa}$, which can ensure the reliable connection performance.

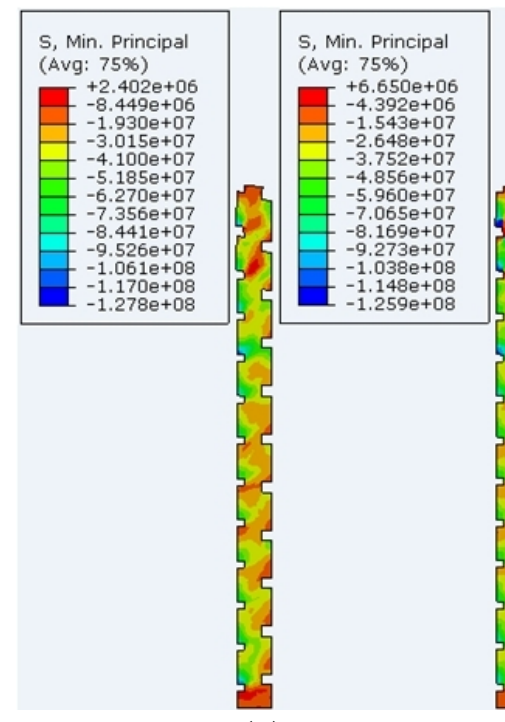

(a)

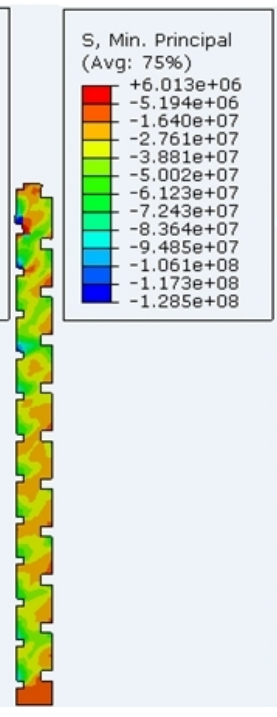

(b)

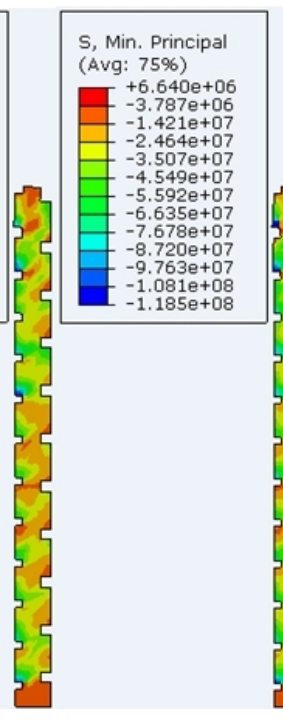

(c)

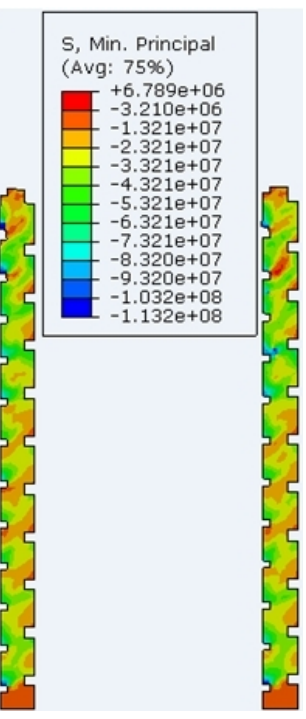

(d) (e)

Fig.3. The minimum principal stress nephogram of grouting-material

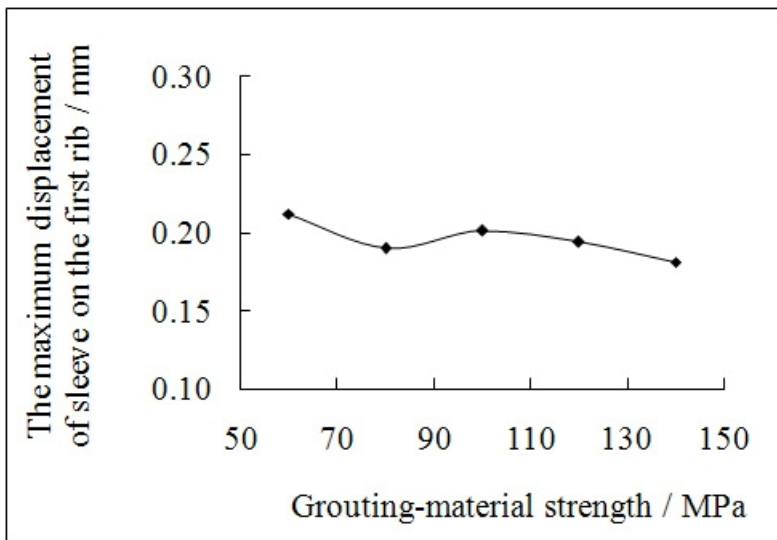

Fig.4. Grouting-material compressive-strength vs. max. displacement of sleeve on the first rib

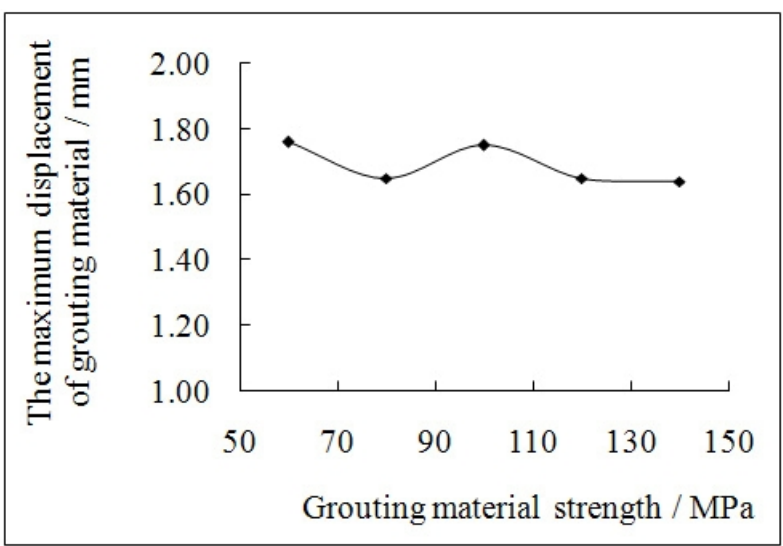

Fig.5. Grouting-material compressive-strength vs. max. displacement of grouting material 
According to numerical simulation, it can be known that the maximum displacement of sleeve occurs at the first rib form loaded end, with the values of $0.212 \mathrm{~mm}, 0.190 \mathrm{~mm}, 0.201 \mathrm{~mm}, 0.194 \mathrm{~mm}$ and $0.181 \mathrm{~mm}$ corresponding to individual grouting-material compressive-strength mentioned above, as shown in Figure4. Similarly, the maximum displacement of grouting material occurs at the contacting surface with the first rib of reinforcement, with the values of $1.76 \mathrm{~mm}, 1.65 \mathrm{~mm}, 1.75 \mathrm{~mm}, 1.65 \mathrm{~mm}$ and $1.64 \mathrm{~mm}$, as shown in Figure5. In addition, with the increase of grouting-material compressive-strength, the maximum displacement of sleeve and grouting material decrease gradually, and the difference value of the maximum displacement between grouting material and sleeve mentioned above represent the pullout displacement of reinforcement bar.

\section{Conclusion}

In this paper, numerical models of grouting-sleeve reinforcement-connection component with different grouting-material compressive-strength were established. Under the action of axial tension load exerted at the end of reinforcement, the stress and displacement distribution at reinforcement, grouting material and sleeve were calculated, and numerical simulation shows conclusions as follows.

(1) When the external load exerted on the end of reinforcement reaches its tensile strength of $570 \mathrm{MPa}$, the maximum Mises stress of sleeve occurs on the middle cross section in axial direction, which is not beyond the tensile strength of sleeve. For grouting-material, umbrella-shaped annular compressed columns are formed to transfer load between reinforcement and sleeve, and the extreme value of minimum principal stress at grouting-material occurs at the surface contacting with the first rib of reinforcement, which is up to its compressive strength.

(2) Grouting-material compressive-strength has little influence upon the stress and displacement distribution at reinforcement and sleeve. Comparatively, with the increase of grouting-material compressive-strength, the largest absolute value of the minimum principal stress at grouting-material could be decrease due to stress redistribution. The compressive-strength of grouting-material should be in the range of $100 \mathrm{MPa}-120 \mathrm{MPa}$, which can ensure the reliable connection performance.

\section{Acknowledgment}

This work was supported by the National Natural Science Foundation of China (No.51278312) and Innovation Team Foundation of Liaoning Education Department (No. LT2012012).

\section{References}

[1] Samuel Yen-Liang Yin. Differential Competition Strategy: R\&D of Ruentex Construction [A]. 4th CECAR Special Forum, 2007: 25-28.

[2] Ziliang Wu. Technology of Grouting-sleeve Reinforcement-connection Component [J]. Housing Industry, 2011 (6): 59-61, (In Chinese).

[3] ABAQUS: ABAQUS Analysis User’s Manual [M]. US, ABAQUS Inc., 2003.

[4] Nobuyuki Izumi, Satoshi Hamada, et al.. Research and Development of Super-high Strength Precast Reinforced Concrete Column [R]. Toda Construction Technical Research Report, No.31, 2002, (In Japanese).

[5] Hiroshi Tokuda et al.. Experimental study of ultra high strength precast reinforced concrete columns [C]. Concrete Institute Proceedings, 2002, 24(2): 727-732, (In Japanese).

[6] Ying Wang, Wenzhong Zheng. Some Cognition to HRB400 Steel [J]. Low Temperature Architecture Technology, 2002(2): 7-9, (In Chinese).

[7] Jinhai Liu, Guolu Li, Xiaoyan Hao, et al.. Correlation between Matrix and Tensile Behavior of Ductile Cast Iron [J]. Foundry Technology, 2009, 30(3): 329-332, (In Chinese). 